\title{
Synthesis of Amino acid Capped Silver Nanoparticles, Characterization and Biological Application
}

\author{
RAMA SHARMA \\ Department of Biotechnology, G.L.A. University, Mathura, India. \\ *Corrsponding author E-mail: dr.rama76@gmail.com \\ http://dx.doi.org/10.13005/ojc/360217
}

(Received: February 29, 2020; Accepted: April 30, 2020)

\begin{abstract}
In the present work, chemical reduction method has been used to synthesize silver nanoparticles using glycine amino acid as a capping agent in different concentrations. The synthesis is optimized for the time by observing the reaction at $30,60,120,180,240,300$ and 360 minutes. The optimum time for this synthesis is 240 minuters. after this time there was no change in absorbance. Ultraviolet-visible spectroscopy and Dynamic light scattering (DLS) techniques are used to characterize these nanoparticles. The surface plasma resonance (SPR) peak in the range between 400-427 nm confirmed the synthesis of silver nanoparticles. These silver nanoparticles are $50-60 \mathrm{~nm}$ in diameter. The antibacterial activity of synthesized nanoparticles is evaluated against E. coli and S. aureus. Nanoparticles show a bactericidal effect on Gram +ve and Gram -ve bacteria. As the concentration of glycine increased, the diameter of the zone of inhibition against E. coli as well as $S$. aureus also increased.
\end{abstract}

Keywords: Silver nanoparticles, Glycine, Ultraviolet-visible spectroscopy, Dynamic light scattering, Antibacterial.

\section{INTRODUCTION}

Nanoparticles are very promising particles because of their exclusive properties ${ }^{1,2}$. Silver nanoparticles (AgNPs) are good antibacterial agents against Gram-positive as well as Gram-negative bacteria. These are used to disinfecting medical equipment and to treat wastewater. Silver itself is a wide range of bactericidal agents therefore silver nanoparticles (AgNPs) are also used as disinfectants ${ }^{3}$.

Studies have shown that AgNPs antimicrobial activity is heavily dependent on size ${ }^{4}$.
Silver nanoparticle's antibacterial properties also rely on there biological media stability, coating form and surface charge ${ }^{5-9}$. Therefore, it is not possible to properly control and measure the bactericidal activity unless the AgNPs are properly stabilized.

Because of the exclusive properties of AgNPs like electrical, optical and magnetic ${ }^{10,11}$, these can be applied in the field of electronics, optics and biological imaging ${ }^{12-17}$. These properties are generally controlled by shape, size, volume, and composition ${ }^{18}$. Different techniquess have been established for the synthesis of AgNPs by controlling some parameters like dimension and phase etc. ${ }^{19-21}$

This is an Open Access article licensed under a Creative Commons license: Attribution 4.0 International (CC- BY). Published by Oriental Scientific Publishing Company @ 2018 
Amino acids are important compounds because they show molecular chirality, the absence of a strongly combined bond, and the molecule's zwitterionic behaviour ${ }^{22}$. Amino acids and vitamins are eco-friendly agents as they can be used as capping agents for the synthesis of nanoparticles ${ }^{23}$ without any harmful effect.

As amino acids have carboxylic as well as amino groups and are water-soluble, in this work capping agent glycine has been used for the synthesis of metal nanoparticles. $\mathrm{AgNO}_{3}$ was reduced to AgNPs in the presence of sodium borohydride and capping agent glycine. Required shape and size of nanoparticles can be obtained with the help of capping agents. Glycine as a capping agent controls the morphology of synthesized particles during the synthesis processes.

\section{EXPERIMENTAL}

\section{Materials}

All the chemicals used in the experiment were from Central Drug House(P) Ltd. (CDH). Triple distilled water was used for all experiments performed in this work. Analytical reagent (AR) grade chemicals like glycine, silver nitrate and sodium borohydride are used to perform this work. Synthesis of silver nanoparticles. ${ }^{24}$

The glycine solutions of $50,100,150$ and 200 millimolar concentration were prepared in triple distilled water. A $20 \mathrm{~mL}$ solution of each concentration was stirred in a conical flask. A 10 $\mathrm{mL}$ of a freshly prepared, ice-cooled solution of $4 \mathrm{mM}$ sodium borohydride was added dropwise in the stirred glycine solution, after the complete addition of sodium borohydride, started the addition of $10 \mathrm{~mL}$ of the aqueous solution of $1 \mathrm{mM}$ silver nitrate $\left(\mathrm{AgNO}_{3}\right)$ dropwise with continuous stirring at room temperature. The ratio of silver to glycine was maintained at 1:50, 1:100, 1:150 and 1:200 mM. After the completion of all addition, each solution color was changed from colorless to dark yellow. As the concentration of each solution is different so color observed of each solution was also different. Stirring was continued for 5-6 hours.

\section{Optimization of the time for synthesis}

The synthesis was optimized at different time intervals $(30,60,120,180,240,300$ and 360 $\mathrm{min}$ ) for $1: 200 \mathrm{mM}$ silver to glycine ratio synthesis. To optimize the synthesis,the synthesised AgNPs were analyzed by taking absorption spectra after each time interval, after a optimum time there was no change in absorbance.

\section{Characterization}

The synthesized AgNPs were characterized by absorption spectra in the wavelength range of 200- $600 \mathrm{~nm}$. The size and polydispersity index was determined by Zetasizer Nano ZS (Malvern Instruments, UK). By UV-Vis spectrophotometer, UV-Vis absorption spectra were obtained to confirm the presence of AgNPs The UV-Vis. spectra correspond to the surface plasma resonance(SPR) of $\mathrm{AgNPs}^{25}$.

\section{Antibacterial Activity Preparation of Media \\ Bacteriology Manual ${ }^{26}$ was followed for the preparation of all media by standard formulation.}

\section{Composition}

$\begin{array}{ll}\text { - } & \text { Peptone }-0.5 \% \\ \text { - } & \mathrm{NaCl}-0.5 \% \\ \text { - } & \text { Agar }-1.5 \% \\ \text { - } & \text { yeast extract }-0.3 \% \\ \text { - } & \mathrm{Distilled} \text { water } \\ \text { - }(6.8) \text { at } 25^{\circ} \mathrm{C} .\end{array}$

Yeast Extract(concentration of $0.3 \%$ $0.5 \%$ ) is prepared by developing baker's yeast, Saccharomyces spp., a plant medium which is rich in carbohydrate. For autolysis the yeast is harvested, washed, and again suspended in water. By heating this autolytic activity is ceased. The so obtained extract of yeast is then filtered and dried.

All the weighed quantities of dry ingredients were dissolved in triple distilled water. This so prepared media was sterilized by autoclaving for 30 min at $121^{\circ} \mathrm{C}$. About $15 \mathrm{~mL}$ of this autoclaved media was poured in Petri dishes aseptically and these Petri dishes were gestated for $24 \mathrm{~h}$ at $37^{\circ} \mathrm{C}$.

By using the inhibition zone method, the antibacterial performance of glycine capped AgNPs was tested against the antibacterial resistance $E$. coli (Gram -ve) and S. aureus (Gram +ve). $10 \mu \mathrm{l}$ of E. coli and $10 \mu \mathrm{l}$ of $S$. aureus were spread into the nutrient agar medium plates. 
Sterile discs were prepared by dipping in $1 \mathrm{mM} \mathrm{AgNO}_{3}$ solution and nano colloidal solution (50, 100, 150 and $200 \mathrm{mM}$ glycine capped AgNPs) synthesized. The so prepared sterile discs were placed in the $E$. coli culture plate in the $S$. aureus culture plate to observe the zone of inhibition. All culture plates were gestated for $24 \mathrm{~h}$ at $37^{\circ} \mathrm{C}$ and the zone of inhibition was noticed.

\section{RESULTS AND DISCUSSION}

\section{Synthesis of silver nanoparticles(AgNPs)}

The AgNPs formation was confirmed by observing the color change of the solution from colorless to dark yellow (Fig. 1) and surface plasma resonance (SPR) band around $420 \mathrm{~nm}$ shows the synthesis of AgNPs in the suspension. The color of the reaction varied as the reaction proceed. Silver ions first combine with glycine and then sodium borohydride as well as silver nitrate, by this process atomic silver reduced to the zero-valent silver.

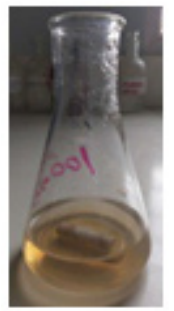

Fig. 1. Silver nanoparticles

\section{Physicochemical characterization}

UV-Vis spectroscopy is a precious method for examining metal nanoparticles because particle size controls the shape and peak position. The UV-Vis. spectra correspond to the surface plasma resonance(SPR) of $\mathrm{AgNPs}^{25}$. The optical absorption band that formed are as follows: for $50 \mathrm{mM}$ glycine sample of AgNPs absorption band at $413 \mathrm{~nm}$, for $100 \mathrm{mM}$ glycine sample of AgNPs absorption band at $411 \mathrm{~nm}$, for $150 \mathrm{mM}$ glycine sample of silver nanoparticle absorption band at $400 \mathrm{~nm}$ and 200 $\mathrm{mM}$ glycine sample of AgNPs absorption band at $427 \mathrm{~nm}$ was found.

The absorption peak at $427 \mathrm{~nm}$ was noticed which shows the presence of spherical AgNPs in the nano colloidal solution. It is also clear from the spectra (Fig. 2) that synthesized AgNPs are monodispersed because polydispersed nanoparticles show an asymmetric peak. Literature shows that dispersibility of nanoparticles depends on the length of the carbon chain of capping molecule ${ }^{27}$.

The concentration of capping agent also affects the dispersibility of nanoparticles. Different concentrations of glycine solution were optimized for the synthesis of AgNPs (Figure 2).

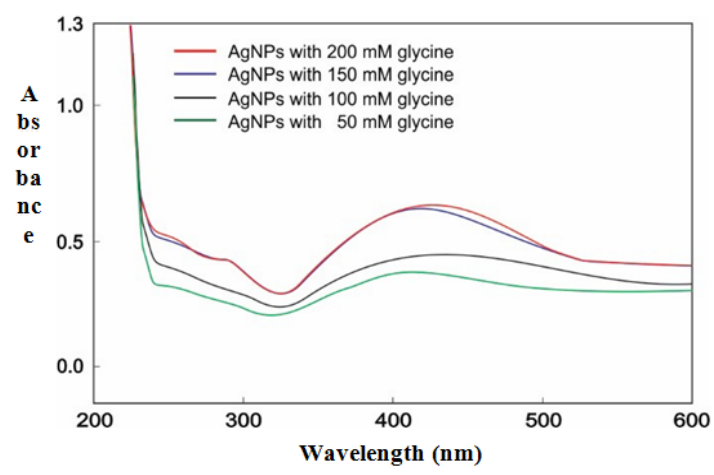

Fig. 2. UV-Vis spectra Wavelength (nm)

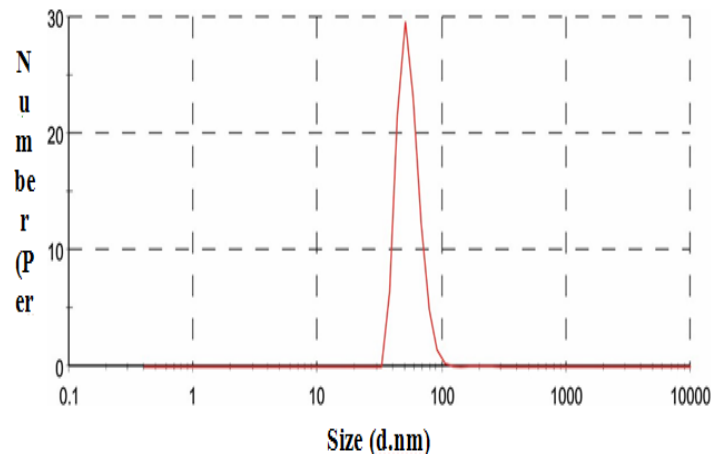

Fig. 3. Particle size

The metal nanoparticles which show surface plasma resonance in the visible range can be characterized by UV-Vis spectroscopy. The surface plasma resonance causes by the swinging of electrons present on the surface of metal nanoparticles when the external energy source is used. By the surface plasma resonance, one can find out the physical properties of the AgNPs as particle size and dielectric medium affect the SPR band ${ }^{28-31}$. In the UV-Vis spectra, a narrow band indicates monodispersed nanoparticles while broadband shows the aggregation of nanoparticles ${ }^{32}$. The size distribution of the particles was determined by DLS and was found to be $50-60$ $\mathrm{nm}$. The most intense particle size is $54.61 \mathrm{dnm}$ with a percentage intensity of $99.7 \%$ (Figure 3 ).

\section{Optimization of time for synthesis}

The synthesis of nanoparticles depends 
on time as the time passes concentration of nanoparticles in the nano colloidal solution increases because as the time passes reduction of metal ion to nanoparticles increases. It is well clear from the absorption spectra of nano colloidal solution at different time intervals. After $4 \mathrm{~h}$ synthesis was optimized i.e. at this time all reduction process completed as there was no increase in the absorption at $5 \mathrm{~h}$ and 6 hours. The characteristic peak Wavelength $(\mathrm{nm})$ was noticed at around 427 $\mathrm{nm}$ as shown in Figure 4.

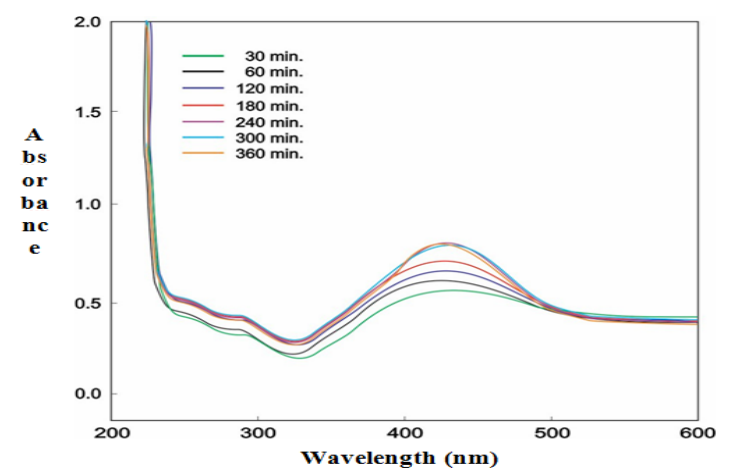

Fig. 4. UV-Vis spectra for the optimization of time

\section{Antibacterial activity}

By using the inhibition zone method, the antibacterial performance of glycine capped AgNPs was tested against the antibacterial resistance of gram-ve E. coli and gram+ve S. aureus. These experimental plates were kept in an incubator for 24 h at $37^{\circ} \mathrm{C}$. The diameter $(\mathrm{mm})$ of the zone of inhibition was measured. Disc in each plate is marked with 50 , 100, 150 and $200 \mathrm{mM}$ (Fig. 5, 6). The zone of inhibition of these different concentrations is reported in Table 1. It is clear from the zone of inhibition that as the concentration of glycine increased in the synthesis of AgNPs bacteriocidal effect also increased.

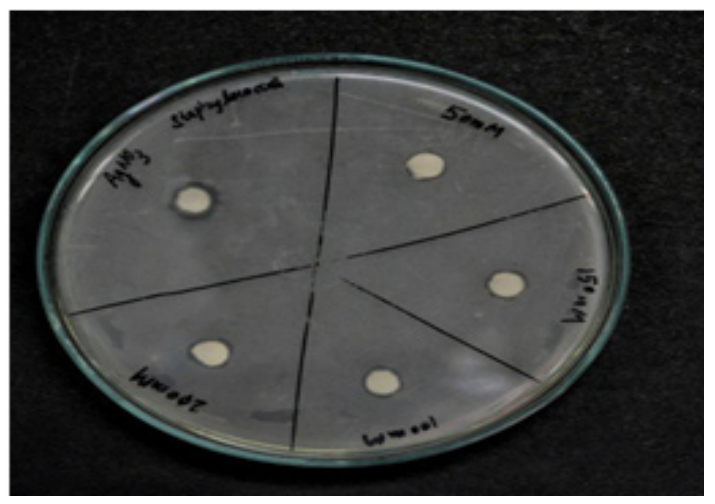

Fig. 5. Zone of inhibition against S. aureus

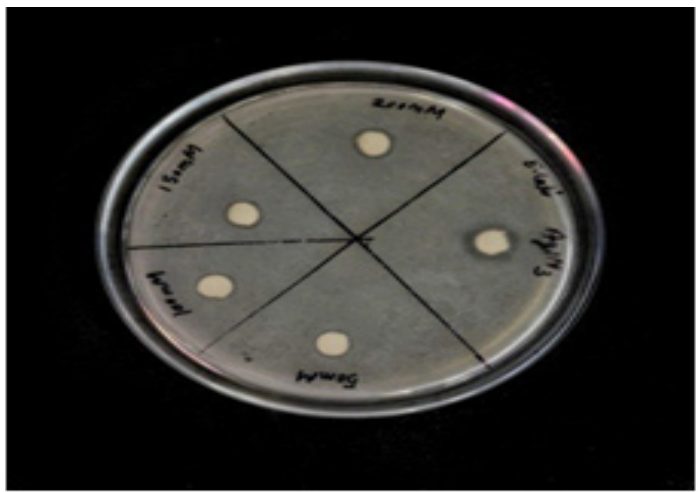

Fig. 6. Zone of inhibition against E. coli

Table 1: Zone of inhibition (in $\mathrm{mm}$ )

\begin{tabular}{ccc}
\hline $\begin{array}{c}\text { Silver nanoparticles of } \\
\text { differentconcentration } \\
\text { of glycine }\end{array}$ & $\begin{array}{c}\text { Zone of inhibition } \\
\text { E. coli culture } \\
\text { plate }\end{array}$ & $\begin{array}{c}\text { Zone of inhibition } \\
\text { S. aureus culture } \\
\text { plate }\end{array}$ \\
\hline $50 \mathrm{mM}$ & $6 \mathrm{~mm}$ & $6 \mathrm{~mm}$ \\
$100 \mathrm{mM}$ & $6 \mathrm{~mm}$ & $7 \mathrm{~mm}$ \\
$150 \mathrm{mM}$ & $7 \mathrm{~mm}$ & $7 \mathrm{~mm}$ \\
$200 \mathrm{mM}$ & $7 \mathrm{~mm}$ & $8 \mathrm{~mm}$ \\
$1 \mathrm{mM} \mathrm{AgNO}$ & $6 \mathrm{~mm}$ & $12 \mathrm{~mm}$ \\
\hline
\end{tabular}

\section{CONCLUSION}

This work successfully shows that capping agent glycine can be used to synthesize AgNPs in an aqueous medium. The AgNPs formed were highly stable and monodispersed as it is cleared from UV-Vis spectra. The synthesized AgNPs are spherical as confirmed by a narrow SPR band ${ }^{30-31}$. The absorbance peaks were remained narrow up to 5 months which shows the monodispersity and stability of synthesized AgNPs. As the concentration of glycine increased, the diameter of the zone of inhibition against $E$. coli as well as $S$. aureus also increased a little.

\section{ACKNOWLEDGMENT}

The author is thankful to the Director, IAH, G.L.A. University, Mathura for financial support of this research.

\section{Conflicts of interest}

The author declares that there is no conflict of interest regarding the publication of this article. 


\section{REFERENCES}

1. Ahmad, A.; Mukherjee, P.; Senapati, S.; Mandal, D.; Khan, M.I.; Kumar, R.; Sastry, M Colloids surfaces B Biointerfaces., 2003, 28, 313-318.

2. Klaus-Joerger, T.; Joerger, R.; Olsson, E.; Granqvist, C.-G. TRENDS Biotechnol., 2001, 19, 15-20.

3. Krzyzewska, I.; Kyzioł-Komosinska, J.; RosikDulewska, C.; Czupioł, J.; AntoszczyszynSzpicka, P. Arch. Environ. Prot., 2016, 42, 87-101.

4. Franci, G.; Falanga, A.; Galdiero, S.; Palomba, L.; Rai, M.; Morelli, G.; Galdiero, M. Molecules. 2015, 20, 8856-8874.

5. Helmlinger, J.; Sengstock, C.; Groß-Heitfeld, C.; Mayer, C.; Schildhauer, T.A.; Köller, M.; Epple, M. RSC Adv., 2016, 6, 18490-18501.

6. Lu, W.; Yao, K.; Wang, J.; Yuan, J. J. Colloid Interface Sci., 2015, 437, 35-41.

7. Pal, S.; Tak, Y.K.; Song, J. M. Appl. Environ. Microbiol., 2007, 73, 1712-1720.

8. Peretyazhko, T.S.;Zhang, Q.; Colvin, V.L. Environ. Sci. \& Technol., 2014, 48, 11954-11961.

9. Shaban, S.M.; Aiad, I.; El-Sukkary, M.M.; Soliman, E.A.; El-Awady, M.Y. Chinese Chem. Lett., 2015, 26, 1415-1420.

10. Li, L.; Hu, J.; Yang, W.; Alivisatos, A.P. Nano Lett., 2001, 1, 349-351.

11. Rao, C.N.R.; Cheetham, A.K. J. Mater. Chem., 2001, 11, 2887-2894.

12. Jain, P.K.; Huang, X.; El-Sayed, I.H.; ElSayed, M.A. Acc. Chem. Res., 2008, 41, 1578-1586.

13. Dahl, J.A.; Maddux, B.L.S.; Hutchison, J.E. Chem. Rev., 2007, 107, 2228-2269.

14. Hutchison, J.E. ACS Nano., 2008, 2, 395-402.

15. Haes, A.J.; Haynes, C.L.; McFarland, A.D.; Schatz, G.C.; Van Duyne, R.P.; Zou, S. MRS Bull., 2005, 30, 368-375.
16. Hutter, E.; Fendler, J.H. Adv. Mater., 2004, 16 , 1685-1706.

17. Evanoff, D.D.; Chumanov, G. J. Phys. Chem. B., 2004, 108, 13948-13956.

18. Mallick, K.; Witcomb, M.; Scurrell, M. Mater. Chem. Phys., 2006, 97, 283-287.

19. McFarland, A.D.; Van Duyne, R.P. Nano Lett., 2003, 3, 1057-1062.

20. Zhang, J.; Malicka, J.; Gryczynski, I.; Lakowicz, J.R. J. Phys. Chem. B., 2005, 109, 7643-7648.

21. Nickel, U.; zu Castell, A.; Pöppl, K.; Schneider, S. Langmuir., 2000, 16, 9087-9091.

22. Nidya, M.; Umadevi, M.; Rajkumar, B.J.M. J. Exp. Nanosci., 2015, 10, 167-180.

23. Kumar Vemula, P.; Aslam, U.; Ajay Mallia, V.; John, G. Chem. Mater., 2007, 19, 138-140.

24. Agasti, N.; Singh, V.K.; Kaushik, N.K. Mater. Res. Bull., 2015, 64, 17-21.

25. Mulvaney, P. Langmuir., 1996, 12, 788-800.

26. Aneja, K.R. Experiments in Microbiology, Plant Pathology and Biotechnology; New Age International., 2003.

27. Phan, C.M.; Nguyen, H.M. J. Phys. Chem. A., 2017, 121, 3213-3219.

28. Nath, S.S.; Chakdar, D.; Gope, G. Nanotrends. 2007, 2, 20-28.

29. Taleb, A.; Petit, C.; Pileni, M.P. J. Phys. Chem. B., 1998, 102, 2214-2220.

30. Noginov, M.A.; Zhu, G.; Bahoura, M.; Adegoke, J.; Small, C.; Ritzo, B.A.; Drachev, V.P.; Shalaev, V.M. Appl. Phys. B Lasers Opt., 2007, 86, 455-460.

31. He, S.; Yao, J.; Jiang, P.; Shi, D.; Zhang, H.; Xie, S.; Pang, S.; Gao, H. Langmuir., 2001, 17, 1571-1575.

32. Bohren, C.F.; Huffman, D.R. Absorption and Scattering of Light by Small Particles., 2007, 82-129. 